\title{
Surgical margins and risk of local recurrence after wedge resection of colorectal pulmonary metastases
}

David B. Nelson, MD, ${ }^{\mathrm{a}}$ Nabihah Tayob, PhD, ${ }^{\mathrm{b}}$ Kyle G. Mitchell, MD, ${ }^{\mathrm{a}}$ Arlene M. Correa, PhD, ${ }^{\mathrm{a}}$

Wayne L. Hofstetter, MD, ${ }^{a}$ Boris Sepesi, MD, ${ }^{a}$ Garrett L. Walsh, MD, ${ }^{a}$ Ara A. Vaporciyan, MD, ${ }^{a}$

Stephen G. Swisher, MD, ${ }^{a}$ Mara B. Antonoff, MD, ${ }^{a}$ Jack A. Roth, MD, ${ }^{a}$ David C. Rice, MD, ${ }^{a}$

Jean-Nicolas Vauthey, MD, ${ }^{\mathrm{c}}$ and Reza J. Mehran, $\mathrm{MD}^{\mathrm{a}}$

\section{ABSTRACT}

Objective: During resection of pulmonary metastases, the need to spare lung parenchyma is often weighed against the increased risk of local recurrence if an inadequate surgical margin is obtained. We sought to identify risk factors for local recurrence after wedge resection of pulmonary metastases of a colorectal origin.

Methods: A retrospective study of patients who underwent a wedge resection for colorectal pulmonary metastases from 2006 to 2016 was performed. Cox regression with robust variance was used to estimate the risk of local recurrence per nodule treated.

Results: We identified 335 patients who underwent 679 wedge resections. The 2-year local recurrence risk for each nodule was $11.8 \%$ (95\% confidence interval, $8.9 \%-14.6 \%$ ), and the 5-year risk was $20.6 \%$ (95\% confidence interval, $16.2 \%$ $24.8 \%$ ). Longer margin length decreased the risk of local recurrence (hazard ratio, 0.434 per additional $\mathrm{cm}$ of length; $P=.015$ ), whereas larger tumor size increased this risk (hazard ratio, 1.520 per additional $\mathrm{cm}$ of size; $P=.012$ ). However, other factors tested, including tumor grade, KRAS mutation status, and response to induction chemotherapy, did not affect recurrence risk. A pathologic margin length of at least half the tumor size was estimated to result in a local recurrence rate $<11 \%$.

Conclusions: Among surgically resected colorectal pulmonary metastases, technical factors related to margin length and tumor size were associated with the risk of local recurrence, whereas tumor grade and $K R A S$ status were not. However, the increased risk of local recurrence with larger tumors was diminished with a sufficient margin length. (J Thorac Cardiovasc Surg 2019;157:1648-55)

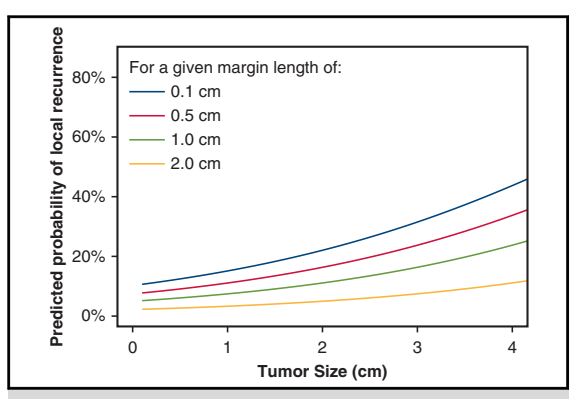

The predicted probability of local recurrence among varying margin lengths.

\section{Central Message}

Risk of local recurrence of colorectal lung metastases is related to margin length and tumor size, but risks imposed by larger tumor size can be offset by achieving a margin of at least half the tumor size.

\section{Perspective}

Wedge resection of colorectal lung metastases is an acceptable treatment option, provided that a margin length of at least half the size of the tumor is obtained. Biologic factors, including tumor grade and KRAS status were not found to influence the risk of local recurrence in our population.

See Commentaries on pages 1656 and pages 1658 .
Colorectal cancer is the third most common cancer in the United States, with approximately 140,000 new cases and

\footnotetext{
From the Departments of ${ }^{\mathrm{a}}$ Thoracic and Cardiovascular Surgery, ${ }^{\mathrm{b}}$ Biostatistics, and 'Surgical Oncology, The University of Texas MD Anderson Cancer Center, Houston, Tex.

Supported by departmental funds.

Read at the 98th Annual Meeting of The American Association for Thoracic Surgery, San Diego, California, April 28-May 1, 2018.

Received for publication April 3, 2018; revisions received Oct 9, 2018; accepted for publication Oct 21, 2018; available ahead of print Jan 9, 2018.

Address for reprints: Reza J. Mehran, MD, Department of Thoracic and Cardiovascular Surgery, The University of Texas MD Anderson Cancer Center, 1515 Holcombe Blvd, Unit 1489, Houston, TX 77030 (E-mail: rmehran@mdanderson.org). 0022-5223/\$36.00

Copyright (c) 2018 by The American Association for Thoracic Surgery https://doi.org/10.1016/j.jtcvs.2018.10.156
}

50,000 deaths projected for 2018. ${ }^{1,2}$ After primary colorectal cancer is resected, the most common extraabdominal site of recurrence is the lung. ${ }^{3}$ Unfortunately, after metastases develop, prognosis is dismal, and the overall survival rate at 5 years is approximately $14 \% .{ }^{4}$ However, retrospective series have shown that resection of pulmonary

Scanning this QR code will take you to the article title page to access supplementary information. To view the AATS Annual Meeting Webcast, see the URL next to the webcast thumbnail.

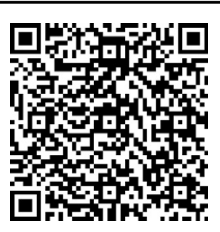




\section{Abbreviation and Acronym \\ VATS $=$ video-assisted thoracoscopic surgery}

metastases may lead to improved disease control and prolonged survival among carefully selected patients. ${ }^{5-8}$ The 5-year survival rate after pulmonary metastasectomy is often reported to be as high as $50 \%$, which is substantially higher than expected for metastatic colorectal cancer and suggests that resection confers a survival benefit. ${ }^{9,10}$ The Pulmonary Metastasectomy in Colorectal Cancer trial ${ }^{11}$ is currently randomizing patients with colorectal pulmonary metastases to either pulmonary metastasectomy or observation to determine whether pulmonary metastasectomy improves survival.

From a purely technical perspective, the optimal surgical approach to resect pulmonary metastases remains a matter of debate. ${ }^{12,13}$ Colorectal pulmonary metastases pose a unique clinical situation in that the risk of new pulmonary metastases is perceived to be higher than for non-small cell lung cancer and the likelihood of nodal metastasis lower. ${ }^{14-16}$ For this reason, resection of colorectal pulmonary metastases is often approached with a wedge resection. However, the risk of local recurrence must be balanced against the need to spare lung parenchyma. We therefore sought to characterize the risk of local recurrence after wedge resection of colorectal pulmonary metastases and to identify risk factors for local recurrence.

\section{METHODS}

\section{Patient Selection}

This retrospective study was approved by the institutional review board at The University of Texas MD Anderson Cancer Center, which waived the requirement for informed consent. A prospectively maintained departmental database was queried to identify patients who underwent wedge resection for pulmonary metastasis of colorectal origin from 2006 to 2016.

\section{Study Design}

This study analyzed the risk of local recurrence per nodule treated. Each observation in the analysis is a single metastatic colorectal nodule, and all resected metastases were included. Specifically, all resected nodules were included as observations if a patient underwent multiple wedge resections, either simultaneously or successively. Covariates were defined according to the time of the procedure for each resected nodule. The exclusion criteria were positive surgical margin, no follow-up imaging, no recording of margin length, and recurrence of a previously treated nodule. Nodules with positive surgical margins were excluded from analysis owing to the high rate of subsequent treatment with an additional therapy (eg, lobectomy and stereotactic radiation). The number of excluded patients and nodules and the reasons for exclusion are presented in the study flowchart (Figure 1).

\section{Follow-up}

Patients were followed with computed tomography or positron emission tomography imaging of the chest at 3- to 6-month intervals. Postoperative radiographs were reviewed by the authors (DBN and RJM) for evidence of local recurrence. Local recurrence was defined as either a positive biopsy or

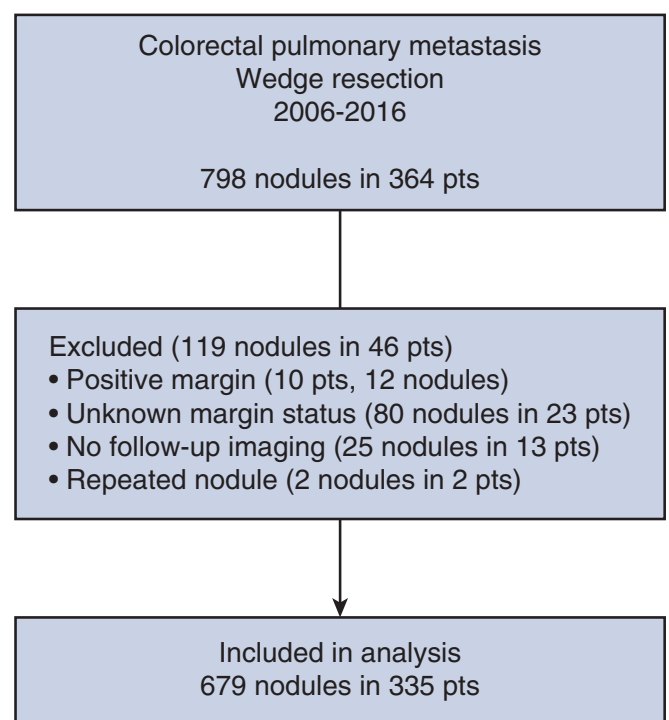

FIGURE 1. Study flowchart showing inclusion and exclusion criteria.

as an enlarging nodule adjacent to the staple line. Biopsy was not required to confirm evidence of recurrence, given that many patients experienced systemic disease and historically did not receive a biopsy as part of their treatment course.

\section{Data Collection and Variable Definitions}

A review of medical records was performed to obtain the following information. The disease-free interval was defined as the time between the date of primary colorectal tumor resection and the date of detection of the metastatic lung nodule. If the primary tumor was not resected, the date of treatment with definitive chemoradiation or local excision was used instead The disease-free interval was set to 0 if pulmonary metastases were detected at the same time as or before resection of the primary tumor. The disease-free interval was calculated for each treated lung nodule. KRAS, NRAS, and TP53 mutation status was collected from chart review when available and reflect either the primary tumor or the metastatic lesion. Response to chemotherapy was defined categorically as decrease in size or number, no change, or increase in size or number. Mixed responses, which include an increase in number but decrease in size, were counted as no change.

The number of lung metastases was defined as the number present before resection. Presence of nodal disease was defined as a positive biopsy result or as mediastinal lymph node enlargement $>1 \mathrm{~cm}$ in the absence of a competing explanation such as lymphoma or sarcoidosis. History of extrathoracic disease was defined as any evidence of metastatic cancer outside of the thorax, such as liver lesions. The pathologic margin length was defined as the distance from the tumor nodule to the cut staple line on the deflated lung. The cut staple line typically removes $0.3 \mathrm{~cm}$ to $0.5 \mathrm{~cm}$. Tumor grade, lymphovascular invasion, and perineural invasion was defined according to the highest degree of differentiation observed on either the metastatic lesion or primary tumor. Lymphovascular invasion and perineural invasion were defined as present if found on either the metastatic lesion or the primary tumor. Tumor size was defined as the size recorded on the gross pathologic examination. The carcinoembryonic antigen level was defined as the last measured level within 1 year before resection. Patients who initially underwent video-assisted thoracoscopic surgery (VATS) and were converted to open surgery were considered open cases for the purposes of this analysis.

\section{Statistical Methods}

Baseline information was reported per patient and per nodule treated. For per-nodule analysis, Cox regression with robust standard errors was used to analyze risk factors for local recurrence, with results adjusted for clustering 
TABLE 1. Baseline characteristics

\begin{tabular}{|c|c|}
\hline Variable & Result \\
\hline \multicolumn{2}{|l|}{ Patient characteristics $(\mathrm{N}=335)$} \\
\hline Age at time of first treatment $(y)$ & $58(21-84)$ \\
\hline \multicolumn{2}{|l|}{ Sex } \\
\hline Male & $193(58)$ \\
\hline Female & $142(42)$ \\
\hline \multicolumn{2}{|l|}{ Primary tumor location } \\
\hline Colon & $188(56)$ \\
\hline Rectum & $147(44)$ \\
\hline \multicolumn{2}{|l|}{ Lymphovascular invasion } \\
\hline Present & $188(56)$ \\
\hline Absent & $94(28)$ \\
\hline Not reported & $53(16)$ \\
\hline \multicolumn{2}{|l|}{ Perineural invasion } \\
\hline Present & $106(32)$ \\
\hline Absent & $90(27)$ \\
\hline Not reported & $139(41)$ \\
\hline \multicolumn{2}{|l|}{ Tumor grade } \\
\hline Well differentiated & $6(2)$ \\
\hline Moderately differentiated & $295(88)$ \\
\hline Poorly differentiated & $34(10)$ \\
\hline \multicolumn{2}{|l|}{$K R A S$ mutation } \\
\hline Present & $135(40)$ \\
\hline Absent & $129(39)$ \\
\hline Not evaluated & $71(21)$ \\
\hline \multicolumn{2}{|l|}{ NRAS mutation } \\
\hline Present & $10(3)$ \\
\hline Absent & $141(42)$ \\
\hline Not evaluated & $184(55)$ \\
\hline \multicolumn{2}{|l|}{ TP53 mutation } \\
\hline Present & $92(27)$ \\
\hline Absent & $35(10)$ \\
\hline Not evaluated & $208(62)$ \\
\hline \multicolumn{2}{|c|}{$\begin{array}{l}\text { Characteristics specific to each nodule at time of resection } \\
\qquad(\mathrm{N}=679)\end{array}$} \\
\hline Disease-free interval (y) & $1.2(0.00-13.7)$ \\
\hline Number of lung metastases & $3(1-27)$ \\
\hline \multicolumn{2}{|l|}{ Preoperative nodal status } \\
\hline Positive & $36(5)$ \\
\hline Negative & $643(95)$ \\
\hline \multicolumn{2}{|l|}{ Approach } \\
\hline Video-assisted thoracoscopic surgery & $106(16 \%)$ \\
\hline Open & $571(84 \%)$ \\
\hline \multicolumn{2}{|l|}{ Extrathoracic disease } \\
\hline Present & $342(50)$ \\
\hline Absent & $337(50)$ \\
\hline \multicolumn{2}{|l|}{ Treatment of all known sites within 6 mo } \\
\hline Yes & $518(76)$ \\
\hline No & $161(24)$ \\
\hline $\begin{array}{l}\text { Preoperative carcinoembryonic antigen } \\
\text { level }(\mu \mathrm{g} / \mathrm{L})\end{array}$ & $2.1(1.2-4.0)^{*}$ \\
\hline Tumor size $(\mathrm{cm})$ & $1.0(0.1-5.0)$ \\
\hline Margin length (cm) & $0.6(0.1-3.5)$ \\
\hline
\end{tabular}

TABLE 1. Continued

\begin{tabular}{lc}
\hline \multicolumn{1}{c}{ Variable } & Result \\
\hline Induction chemotherapy $\dagger$ & \\
Yes & $296(44)$ \\
No & $383(56)$ \\
Response to induction chemotherapy & \\
Smaller or fewer metastases & $68(10)$ \\
No change & $103(15)$ \\
Larger or new metastases & $125(18)$ \\
Not given & $383(56)$ \\
Adjuvant chemotherapy & \\
Yes & $213(31)$ \\
No & $466(69)$ \\
\hline
\end{tabular}

Values are presented as $\mathrm{n}(\%)$ or median (range). *Value presented as median (interquartile range). $\nmid$ Before resection of lung metastasis.

by patient to account for the similarity of tumor histology within an individual patient. Kaplan-Meier curves were constructed to assess the risk of local recurrence, stratified by tumor size. Log-rank test with robust standard errors was used to compare risk of local recurrence by tumor size. The Cox regression model was used predict the risk of local recurrence within 2 years with varying tumor sizes and margin lengths, with other covariates set to their median or mode. All statistical analysis was performed using $\mathrm{R}$ version 3.3.2 (R Foundation for Statistical Computing, Vienna, Austria).

\section{RESULTS}

\section{Patient and Tumor-Related Characteristics}

We initially identified 345 patients who underwent 771 wedge resections for colorectal pulmonary metastases (Figure 1). After exclusion of nodules with a positive surgical margin and those with unknown margin length, the analysis included 335 patients who underwent 679 wedge resections (Table 1). Although only R0 resections were included in the analysis, not all lung resections were performed with curative intent; 161 of $679(24 \%)$ resections did not have treatment of all sites of known disease at or near the time of resection. The most common indication for lung resection without curative intent was to obtain tissue specimens to guide the choice of systemic therapy. Because our primary outcome was local recurrence, we elected to include patients who did not have local control at all known disease sites. VATS was used for $106(16 \%)$ nodules. Among the VATS cases, the margin length was longer (median $0.7 \mathrm{~cm}$ vs $0.5 \mathrm{~cm} ; P=.044$ ).

\section{Risk of Local Recurrence}

After resection, the risk of local recurrence within 2 years for each nodule was $11.8 \%$ (95\% confidence interval [CI], $8.9 \%-14.6 \%)$, and the risk within 5 years was $20.6 \%(95 \%$ CI, $16.2 \%-24.8 \%$ ). The risk of local recurrence varied by tumor size. For subcentimeter nodules, the risk of local recurrence within 2 years was $8.8 \%(95 \% \mathrm{CI}, 4.9 \%$ $12.6 \%$ ); for 1 - to 2 -cm nodules, the risk was $12.0 \%$ (95\% CI, $8.0 \%-15.8 \%$ ), and for nodules larger than $2 \mathrm{~cm}$, the risk was $30.9 \%$ (95\% CI, $10.9 \%-46.5 \%)$. 
Kaplan-Meier curves showing the rate of local control by tumor size are shown in Figure 2.

\section{Factors Associated With Increased Risk of Local Recurrence}

A Cox regression model with robust standard errors was used to identify factors that were associated with an increased risk of local recurrence. We used robust standard errors because the risk of local recurrence was calculated per resected tumor nodule; this type of model statistically adjusts for the more-similar outcomes associated with multiple tumors from the same patient, which are presumably attributable to their similar biology. Results of this multivariate regression analysis are shown in Table 2.

Longer margin length decreased the risk of local recurrence (hazard ratio, 0.434 per additional centimeter of length; $P=.015$ ), whereas larger tumor size increased this risk (hazard ratio, 1.520 per additional centimeter of size; $P=.012$ ). However, the other factors tested, including tumor grade, presence of KRAS mutation, and response to induction chemotherapy, were not predictive of local recurrence. An additional ad-hoc analysis that included VATS approach was performed and revealed that VATS was not associated with the risk of local recurrence (data not shown). The effect of margin length on the risk of local recurrence was similar regardless of clinical context; that is, no interaction with other measured variables was present.

\section{Influence of Margin Length on Tumor Recurrence}

We estimated the influence of margin length and tumor size on the risk of local recurrence using the estimated multivariate Cox regression model. These findings are summarized in Figure 3. For 1-cm tumors, the risk of local recurrence within 2 years was $11.08 \%$ (95\% CI, 5.39\%-

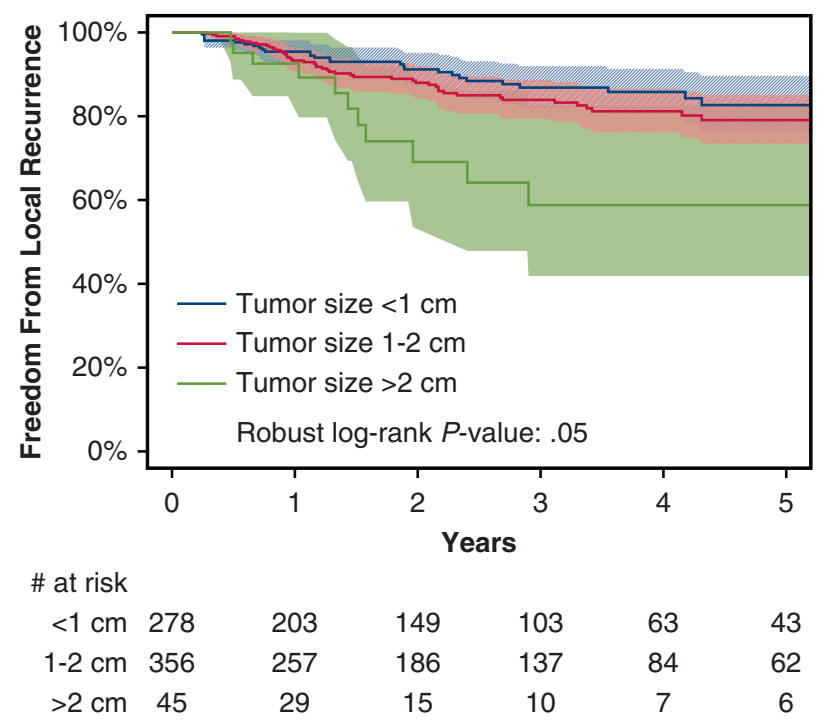

FIGURE 2. Local recurrence stratified by tumor size.
TABLE 2. Factors associated with risk of local recurrence

\begin{tabular}{llc}
\hline \multicolumn{1}{c}{ Factor } & \multicolumn{1}{c}{$\begin{array}{c}\text { Hazard ratio } \\
\text { (95\% confidence } \\
\text { interval) }\end{array}$} & P value \\
\hline Margin length (per cm) & $0.434(0.222-0.848)$ & .015 \\
Tumor size (per cm) & $1.519(1.095-2.107)$ & .012 \\
\hline Differentiation & & \\
Well-moderate & Reference & \\
Poor & $0.950(0.383-2.355)$ & .912 \\
KRAS mutation & & \\
Present & Reference & \\
Absent & $1.245(0.710-2.181)$ & .445 \\
Not evaluated & $0.114(0.026-0.503)$ & .004 \\
\hline Disease-free interval (per y) & $0.990(0.884-1.108)$ & .858 \\
Lymphovascular invasion & & \\
Present & Reference & \\
Absent & $1.005(0.522-1.932)$ & .989 \\
Not reported & $1.865(1.031-3.374)$ & .039 \\
\hline Response to chemotherapy & & \\
No chemotherapy given & Reference & .992 \\
Smaller or fewer metastases & $0.996(0.456-2.175)$ & .428 \\
No change & $1.052(0.491-2.255)$ & \\
Larger or new metastases & $1.304(0.676-2.516)$ &. \\
\hline
\end{tabular}

$16.43 \%$ ) provided that a $0.5-\mathrm{cm}$ margin was obtained and $7.45 \%(95 \%$ CI, $2.77 \%-11.90 \%)$ provided that a $1-\mathrm{cm}$ margin was obtained. For 2-cm tumors, the risk of local recurrence was $11.09 \%$ (95\% CI, $4.44 \%-17.28 \%)$ provided that a $1-\mathrm{cm}$ margin was obtained and $4.97 \%(95 \%$ CI, $0.00 \%-10.22 \%$ ) provided that a $2-\mathrm{cm}$ margin was obtained. For 4-cm tumors, the local recurrence rate was $23.76 \%$ (95\% CI, $0.54 \%-55.43 \%$ ) provided that a $1-\mathrm{cm}$ margin was obtained and $11.11 \%(95 \%$ CI, $0.00 \%$ $23.76 \%$ ) provided that a $2-\mathrm{cm}$ margin was obtained. Thus, we estimated that a margin length of at least half the tumor size resulted in a local recurrence risk $<11 \%$

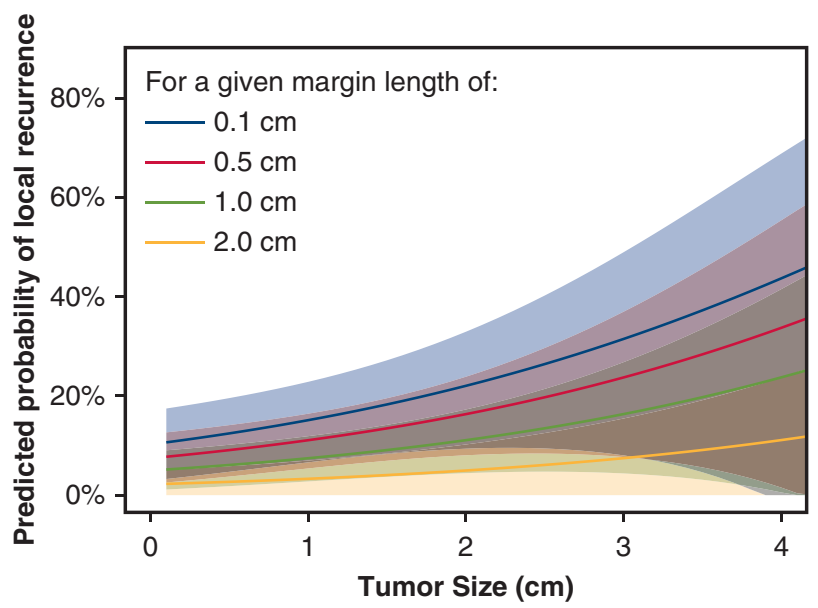

FIGURE 3. The predicted probability of local recurrence among varying margin lengths. 


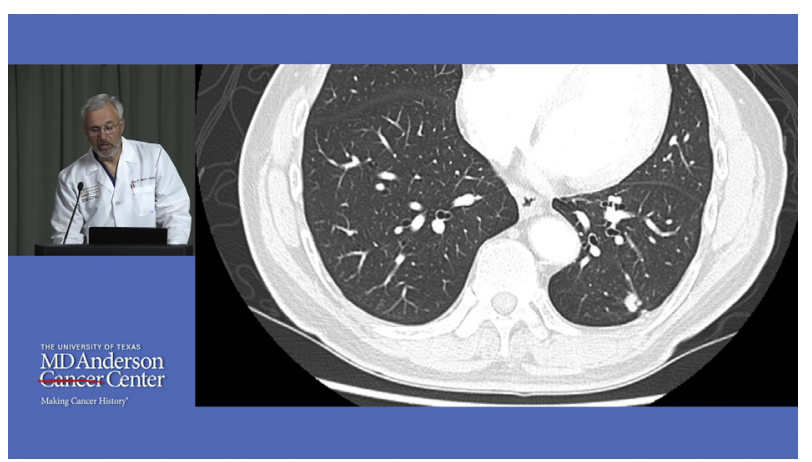

VIDEO 1. Video presentation of key findings. Video available at: https:// www.jtcvs.org/article/S0022-5223(18)33149-0/fulltext.

within 2 years. A margin length of at least the size of the tumor resulted in a local recurrence risk $<7 \%$ within 2 years. These results were most valid for tumors of $3 \mathrm{~cm}$ or less, which made up 666 of the 679 nodules in our dataset.

\section{DISCUSSION}

Among surgically resected colorectal pulmonary metastases, technical factors related to margin length and tumor size were associated with the risk of local recurrence. Tumor grade and KRAS mutation status were not associated with the risk of local recurrence in our population. However, the increased risk of local recurrence with larger tumors was diminished with a sufficient margin length.

To our knowledge, this is the most comprehensive and largest study investigating the influence of margin length on local recurrence risk after resection of colorectal pulmonary metastases. Welter and colleagues ${ }^{17}$ investigated satellite tumor cells in the vicinity of 17 resected pulmonary colorectal metastases and found that nearly all satellite tumor cells were found within $7.4 \mathrm{~mm}$ of the metastatic tumor. These satellite tumor cells, often representing unresected cancer, are a major risk factor for local recurrence. ${ }^{18}$ Welter and colleagues ${ }^{17}$ detected no statistically significant correlation between satellite tumor cell-tumor distance and tumor size; however, our results show that larger tumors are associated with an increased risk of local recurrence. Although our study lacks histologic correlates, a trend toward increased satellite tumor cell distance among larger tumors seen in the study by Welter and colleagues ${ }^{17}$ suggests that an increase in satellite tumor cells around larger tumors may explain the increased risk of local recurrence with larger tumors.

We expected to find that biologic factors such as tumor grade or the presence of lymphovascular invasion would drive the risk of local recurrence, either through increasing lymphatic spread or through propagating satellite tumor cells, as discussed above. The presence of KRAS mutations, for instance, has been shown to be associated with an increased risk of positive margins or shorter margin length after resection of colorectal liver metastases. ${ }^{19}$ Identifying these aggressive tumors preoperatively may help with operative planning. We were surprised to find that none of the measured biologic factors that we tested were associated with the risk of local recurrence. This may be explained in 1 of 2 ways. It is possible that technical issues, such as tumor size and margin length, drive the risk of local recurrence, irrespective of how aggressive the tumor is. A second possible explanation is that tumor biology may be important, but better, still unmeasured markers are needed. More effort is required to identify preoperatively available biomarkers associated with aggressive behavior of colorectal pulmonary metastases.

Although a plethora of studies have evaluated factors associated with overall survival or recurrence-free survival after pulmonary metastasectomy, ${ }^{5-9,20-23}$ our study is novel in its focus on the risk of staple-line failures. However, our study has some limitations. First, there is a risk of residual confounding in this retrospective analysis. As mentioned above, there may be as-yet unmeasured biologic factors that influence the risk of local recurrence, although our study was thorough in including mutation status. Second, our study, by design, was limited in scope to the risk of local staple-line failure, but there are other important considerations in operative planning, such as the risk of nodal metastasis, ${ }^{14-16}$ rate of pathologic upstaging with nodal harvest, and overall survival. However, most studies investigating overall survival after resection of colorectal pulmonary metastases have bias owing to their careful selection. Third, studies vary with regard to the method used to measure margin length. ${ }^{24}$ We measured from the cut staple line, which may add approximately 0.3 to $0.5 \mathrm{~cm}$ to measurements taken before the cut, and is measured on a deflated lung. Fourth, nearly all the resected nodules were $\leq 3 \mathrm{~cm}$, which limits the generalizability to smaller nodules. However, most nodules larger than $3 \mathrm{~cm}$ are not candidates for wedge resection. Finally, our results with regard to the importance of margin length after resection of colorectal pulmonary metastases are probably not generalizable to other organs, because prior data has shown that 1-mm margins may be sufficient for resection of colorectal liver metastases. ${ }^{25}$ Our results may also be different among pulmonary metastases of another origin.

\section{CONCLUSIONS}

We found that wedge resection of colorectal pulmonary metastases results in an adequate rate of local control provided that a pathologic margin length of at least half the tumor size was obtained. The pathologic margin length is measured after the staple line is cut. These results may prove to be critically helpful for operative planning and to maximize parenchyma preservation. Furthermore, we found that technical factors related to margin length and tumor size affected the risk of local recurrence, whereas measured biologic factors, including tumor grade and 
$K R A S$ mutation status were not found to be relevant. Further research may be helpful in identifying ideal candidates who would benefit most from a local control strategy for treating pulmonary metastases of a colorectal origin (Video 1).

\section{Webcast}

You can watch a Webcast of this AATS meeting presentation by going to: https://aats.blob.core.windows.net/ media/18Apr30/25ABC\%202.General $\%$ 20Thoracic $\% 20$ SS/S72\%20-\%20Part\%202/S72_4_webcast_044949126. mp4.

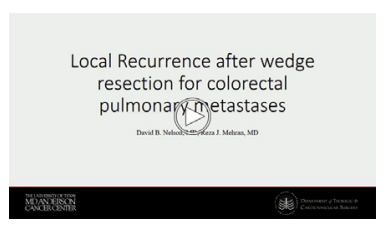

\section{Conflict of Interest Statement}

Authors have nothing to disclose with regard to commercial support.

\section{References}

1. Miller KD, Siegel RL, Lin CC, Mariotto AB, Kramer JL, Rowland JH, et al. Cancer treatment and survivorship statistics, 2016. CA Cancer J Clin. 2016;66: 271-89.

2. Siegel RL, Miller KD, Jemal A. Cancer statistics, 2018. CA Cancer J Clin. 2018; 68:7-30.

3. Manfredi S, Bouvier AM, Lepage C, Hatem C, Dancourt V, Faivre J. Incidence and patterns of recurrence after resection for cure of colonic cancer in a well defined population. Br J Surg. 2006;93:1115-22.

4. Siegel RL, Miller KD, Fedewa SA, Ahnen DJ, Meester RGS, Barzi A, et al. Colorectal cancer statistics, 2017. CA Cancer J Clin. 2017:67:177-93.

5. Pfannschmidt J, Hoffmann H, Dienemann H. Reported outcome factors for pulmonary resection in metastatic colorectal cancer. J Thorac Oncol. 2010;5: S172-8.

6. Welter S, Jacobs J, Krbek T, Krebs B, Stamatis G. Long-term survival after repeated resection of pulmonary metastases from colorectal cancer. Ann Thorac Surg. 2007;84:203-10

7. Gonzalez M, Poncet A, Combescure C, Robert J, Ris HB, Gervaz P. Risk factors for survival after lung metastasectomy in colorectal cancer patients: a systematic review and meta-analysis. Ann Surg Oncol. 2013;20:572-9.

8. Pfannschmidt J, Dienemann H, Hoffmann H. Surgical resection of pulmonary metastases from colorectal cancer: a systematic review of published series. Ann Thorac Surg. 2007;84:324-38.

9. Blackmon SH, Stephens EH, Correa AM, Hofstetter W, Kim MP, Mehran RJ, et al. Predictors of recurrent pulmonary metastases and survival after pulmonary metastasectomy for colorectal cancer. Ann Thorac Surg. 2012;94:1802-9.

10. Guerrera F, Mossetti C, Ceccarelli M, Bruna MC, Bora G, Olivetti S, et al. Surgery of colorectal cancer lung metastases: analysis of survival, recurrence and resurgery. J Thorac Dis. 2016;8:1764-71.

11. Treasure T, Fallowfield L, Lees B, Farewell V. Pulmonary metastasectomy in colorectal cancer: the PulMiCC trial. Thorax. 2012;67:185-7.

12. Hernandez J, Molins L, Fibla JJ, Heras F, Embun R, Rivas JJ. Role of major resection in pulmonary metastasectomy for colorectal cancer in the Spanish prospective multicenter study (GECMP-CCR). Ann Oncol. 2016;27:850-5.

13. Higashiyama M, Tokunaga T, Nakagiri T, Ishida D, Kuno H, Okami J. Pulmonary metastasectomy: outcomes and issues according to the type of surgical resection. Gen Thorac Cardiovasc Surg. 2015;63:320-30.
14. Pfannschmidt J, Klode J, Muley T, Dienemann H, Hoffmann H. Nodal involvement at the time of pulmonary metastasectomy: experiences in 245 patients. Ann Thorac Surg. 2006;81:448-54.

15. Shiono S, Matsutani N, Okumura S, Nakajima J, Horio H, Kohno M, et al. The prognostic impact of lymph-node dissection on lobectomy for pulmonary metastasis. Eur J Cardiothorac Surg. 2015;48:616-21.

16. Ercan S, Nichols FC, Trastek VF, Deschamps C, Allen MS, Miller DL, et al Prognostic significance of lymph node metastasis found during pulmonary metastasectomy for extrapulmonary carcinoma. Ann Thorac Surg. 2004;77:1786-91.

17. Welter S, Theegarten D, Trarbach T, Maletzki F, Stamatis G, Tötsch M. Safety distance in the resection of colorectal lung metastases: a prospective evaluation of satellite tumor cells with immunohistochemistry. J Thorac Cardiovasc Surg. 2011:141:1218-22.

18. Shiono S, Ishii G, Nagai K, Yoshida J, Nishimura M, Murata Y, et al. Predictive factors for local recurrence of resected colorectal lung metastases. Ann Thorac Surg. 2005;80:1040-5.

19. Brudvik KW, Mise Y, Chung MH, Chun YS, Kopetz SE, Passot G, et al. RAS mutation predicts positive resection margins and narrower resection margins in patients undergoing resection of colorectal liver metastases. Ann Surg Oncol. 2016; $23: 2635-43$

20. Shiono S, Okumura T, Boku N, Hishida T, Ohde Y, Sakao Y, et al. Outcomes of segmentectomy and wedge resection for pulmonary metastases from colorectal cancer. Eur J Cardiothorac Surg. 2017;51:504-10.

21. Shiono S, Ishii G, Nagai K, Yoshida J, Nishimura M, Murata Y, et al. Histopath ologic prognostic factors in resected colorectal lung metastases. Ann Thorac Surg. 2005;79:278-82.

22. Vogelsang H, Haas S, Hierholzer C, Berger U, Siewert JR, Präuer H. Factor influencing survival after resection of pulmonary metastases from colorectal cancer. Br J Surg. 2004;91:1066-71.

23. Inoue M, Ohta M, Iuchi K, Matsumur A, Ideguchi K, Yasumitsu T, et al. Benefits of surgery for patients with pulmonary metastases from colorectal carcinoma. Ann Thorac Surg. 2004;78:238-44.

24. Sawabata N. Who should decide margin length in pulmonary excision of lung cancer? J Thorac Cardiovasc Surg. 2014;148:370-1.

25. Vandeweyer D, Neo EL, Chen JWC, Maddern GJ, Wilson TG, Padbury RT. In fluence of resection margin on survival in hepatic resections for colorectal liver metastases. HPB (Oxford). 2009;11:499-504.

Key Words: wedge resection, metastasectomy, local recurrence, colorectal

\section{Discussion}

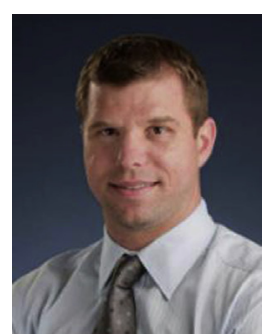

Dr Marcelo Cypel (Toronto, Ontario, Canada). Thank you very much. Dr Waddell was supposed to be here discussing this article. Unfortunately he was not able to cancel.

I thank the authors for sending the manuscript to me to review it. I would like to commend this important study evaluating margins of resection and local recurrence in patients undergoing wedge resections for pulmonary metastases. As you have seen, the main conclusions were that we should be having at least a margin that is half the size of the tumor nodule.

I have 2 questions for you. Number 1, did you look at predictors of having a positive or close margin, for example, video-assisted thoracoscopic surgery versus open, more peripheral versus a bit deeper lesion? 


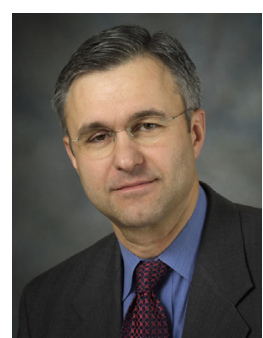

Dr Mehran (Houston, Tex). As far as a risk factor for the margin, that is pretty much surgeon dependent. But I have to tell you that in the video-assisted thoracoscopic surgery group of patients we found that the margin was always bigger, despite the fact that often there is no tactile sensation to feel where the lesion is.

Dr Cypel. My second question: You also mentioned, and they were excluded here, that $24 \%$ of your colorectal cancer lung metastases were performed for noncurative intent. So that seems to be a high percentage of cases. Could you expand a bit on the main reasons for that?

Dr Mehran. This is coming from the article. In our institution, up until recently, we had a number of protocols evaluating CTLA-4 [cytotoxic T-lymphocyte associated protein 4] and other vaccine studies to treat colorectal metastases. So we were asked to remove metastases, and a needle biopsy or a core biopsy was simply not enough material for the pathologists and the scientists to culture the tissue for the vaccine.

Dr Cypel. My last question: These margins were measured after fixation, paraffin blocks, and so going forward do you think the results would be valid for measuring at the time of surgery after passing the stapler? Usually you may have a 3 or $4 \mathrm{~mm}$ difference there.

Dr Mehran. Yes, indeed, I did mention that. The margin was measured with a deflated lung, which is also the situation when you operate on the patient, right? The lung is deflated.

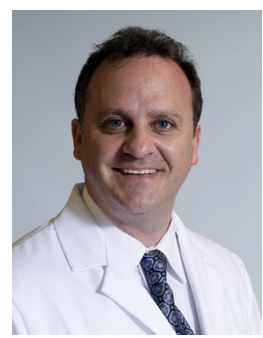

Dr Michael Lanuti (Boston, Mass). Is that with the staple line in place or with the staple line cut open?

Dr Mehran. Without the staple line.

Dr Lanuti. So the staple line in the Tri-Staple is about $5 \mathrm{~mm}$. Are you using Tri-Staple [Medtronic, Minneapolis, Minn]?

Dr Mehran. Yes.

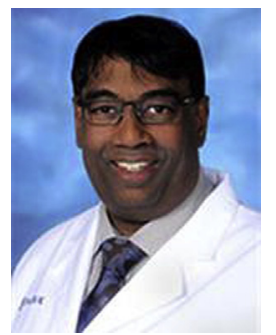

Dr Hiran Fernando (Falls Church, Va). Reza, congratulations again. You looked at things that affected biology, and I know from the data set that you presented yesterday some of these patients were clinically nodal positive, but you didn't factor that as an influence on recurrence. Also, you are going to be limited by the number of metastases that you have to deal with in a patient and you are not always going to be able to get a good margin. So did you factor in also the number of metastases per patient as a risk factor for recurrence as well, because that may be a confounding effect in this.

Dr Mehran. You are absolutely correct. I did not. I was focused on the rate of local recurrence at each nodule individually, trying to find a risk factor for this vexing problem.

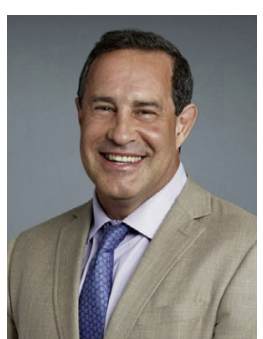

Dr Robert J. Cerfolio (New York, NY). I agree with you. Your point of ipsilateral number, not overall but ipsilateral, should be a factor. You should probably try to include that, if you could.

Dr Lanuti. Well, I would say all, because if you are taking someone in for 10 nodules, you are going to get a close margin rather than large margins, right, as opposed to 1 or 2 nodules.

Dr Mehran. Absolutely.

Dr Fernando. And there is going to be some effect on biology as well, because if a patient has multiple metastases, it's going to have some effect on biology.

Dr Cerfolio. And it's also more likely to recur close to your staple line from a satellite nodule. It has nothing to do with your resections. So I do think that needs to be looked at.

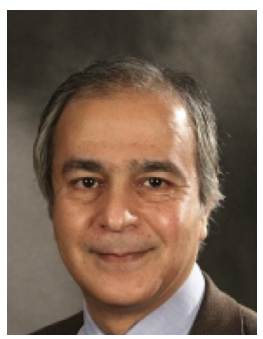

Dr Nasser Altorki (New York, NY). Congratulations on a great presentation. I have a couple of questions for you. Did I understand you correctly when you put the example of a $1 \mathrm{~cm}$ nodule that if you had doubled the margin size to 2 the recurrence rate will essentially be close to 0 ?

Dr Mehran. That is correct.

Dr Altorki. What is the implication of that for a $2-\mathrm{cm}$ metastases? Are we now going to advocate doing a lobar resection for those?

Dr Mehran. A very good point. We did not have a lot metastases measuring $2 \mathrm{~cm}$ and more. So in the equation that was created to measure the risk of local recurrence based on the size of the tumor, larger tumor size is underrepresented, but based on this equation, sure enough it looks like we need to have a large margin around a $2-\mathrm{cm}$ tumor. Now, is this feasible? No. You can't do a lobe just fora metastasis, so here comes the judgment of the physician and the pulmonary reserve of the patient. So you have to use your judgment and accept the fact that this patient may recur locally if the margin is small. 
Dr Altorki. The other issue is, we think of margins in 2 dimensions but it is really a 3 -dimensional thing. There is that deep margin, and we are never really sure about that deep margin. It would be great if there was some software that would guide you in that regard. Did you look at the margin in that way or was it impossible in a retrospective study to look at that? I would just think it wasn't.

Dr Mehran. Dr Sato earlier this afternoon presented great data with localization trying to get a 3-dimensional dimension.

Dr Altorki. But he has the same problem. I want to ask him that question, too, because I don't think he can do that.

Dr Mehran. He does have that problem, and in my case here, it's impossible.

Dr Cerfolio. Well, it's currently not clinically available but it's not impossible. It's cost sensitive. But of course this is why a computerized system could be utilized-you don't have to use the word robotic - that is going to allow us to tag the cancer, which can be done, because we can tag nerves, arteries, vessels, and other things and actually see them by changing the camera with resolution and/or by tagging the mass. It can be done. So at some point we are going to be there very soon.

Dr Altorki. My last question is, are you now looking at spot cytology in the operating room when you do a wedge resection?

Dr Lanuti. Like a touch prep.

Dr Cerfolio. Of the staples, of washing the staples.

Dr Altorki. We have tried it, and, believe it or not, you can see some cells there.

Dr Mehran. If there is a doubt about the margin length, I just send the tissue for a frozen section analysis. So we don't use at MD Anderson touch prep on the specimen. We use frozen section.
Dr Lanuti. Can I just poll the audience, how many people actually do a touch prep and frozen section after a wedge? Almost nobody.

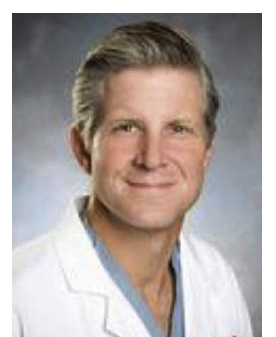

Dr Scott Swanson (Boston, Mass). A quick question. I thought Nasser was going to go there, but he didn't. When you have bigger lesions and you are trying to get a deep margin, it's difficult. Did you look at where these lesions were located relative to the visceral pleural surface or peripheral versus central, because a $3-\mathrm{cm}$ peripheral nodule is actually wedgeable, a $2-\mathrm{cm}$ central nodule is not. Is that in there anywhere in this analysis?

Dr Mehran. You are right, Scott, this is an issue. Let's say we have a central lesion in the middle of the right upper lobe. It may be very difficult to offer this patient some sort of pulmonary resection short of doing a lobectomy. In these particular cases we rely on other ablative technologies, just like stereotactic body radiation therapy, which was discussed yesterday, or radiofrequency ablation. These things have to be individualized.

Dr Swanson. But in your analysis did you look at the computed tomography scan locations relative to the outcome of recurrence?

Dr Mehran. No, Scott, we did not.

Dr Lanuti. So, remember, there is a sloppy local option that has been well described, a precision cautery; that is, coring it out, which of course goes against all of this. But well described.

Dr Cerfolio. That was a very well presented and a very well-discussed article. Excellent. Thank you. 